\title{
Replacing Oxamniquine by Praziquantel against Schistosoma mansoni Infection in a Rural Community from the Sugar-cane Zone of Northeast Brazil: an Epidemiological Follow-up
}

\section{Lilian Beck/ ${ }^{+}$, Tereza Cristina Favre, Otávio Sarmento Pieri, Luciana Carvalho Zani, Glauce Gajo Domas, Constança Simões Barbosa*}

\author{
Laboratório de Ecologia e Controle de Moluscos Vetores, Departamento de Biologia, Instituto Oswaldo Cruz- \\ Fiocruz, Av. Brasil 4365, 21045-900 Rio de Janeiro, RJ, Brasil *Departamento de Parasitologia, \\ Centro de Pesquisas Aggeu Magalhães-Fiocruz, Recife, PE, Brasil
}

A group of 52 villagers was followed-up for three years regarding Schistosoma mansoni infection. All villagers were periodically surveyed by the Kato-Katz method. In March 1997 and March 1998 the positives were treated with oxamniquine (15-20 mg/kg), and in March 1999, with praziquantel (60 mg/ $\mathrm{kg})$. All infection indices decreased substantially between March 1999 and March 2000: prevalence of infection (from $32.7 \%$ to $21.2 \%$ ), prevalence of moderate/heavy infection (from $7.7 \%$ to $1.9 \%$ ), intensity of infection (from $23.1 \mathrm{epg}$ to $7.4 \mathrm{epg}$ ) and reinfection (from $35.7 \%$ to $14.3 \%$ ). Negativation increased from 53.8 to 82.4. An optimistic prognostic is assumed in the short term for the introduction of praziquantel in the study area.

Key words: schistosomiasis - control - chemotherapy - Northeast - Brazil

Araújo is a small rural village in the municipality of São Lourenço da Mata, State of Pernambuco, which has held alarming prevalence levels despite four chemotherapy campaigns with oxamniquine against schistosomiasis by the Fundação Nacional de Saúde (Funasa), as follows: 30.2\% (May 1979), 22.4\% (September 1982), 79.2\% (March 1986) and 71.7\% (January 1996). In March 1997, all villagers over one year of age were surveyed by the KatoKatz (Katz et al. 1972) method (one sample; two slides) and the positives were given a single oral dose (15-20 mg/kg of body weight) of oxamniquine. Kato-Katz surveys (two samples; two slides each) of the villagers were made in July 1997 and March 1998, and the positives from the latter were treated with oxamniquine. The villagers were surveyed

\footnotetext{
The authors dedicate this paper to the Oswaldo Cruz Institute in honor of the centenary of its foundation, May 25th 1900.

This work was partially supported by the Conselho Nacional de Desenvolvimento Científico e Tecnológico, CNPq.

${ }^{+}$Corresponding author. E-mail: lbeck@ioc.fiocruz.br Received 14 May 2001 Accepted 25 July 2001
}

again in July 1998 and March 1999. The positives from this survey were then treated with praziquantel $(60 \mathrm{mg} / \mathrm{kg})$, and the villagers were subsequently surveyed in July 1999 and March 2000. A socioeconomic questionnaire was applied house-tohouse in March 1997 and September 1999. Relative abundance and natural infection of the local snail host, Biomphalaria straminea, were estimated monthly as described by Pieri et al. (1998) and Favre (1999), respectively. Aiming to gather epidemiological information about the replacement of oxamniquine by praziquantel in the village, a follow-up group of fully complying villagers was then identified, from which the following indices were calculated (WHO 1993): (i) prevalence of infection - percentage of surveyed persons with eggs per gram of feces (epg) $>0$; (ii) prevalence of moderate to heavy infection - percentage of surveyed persons with epg >100; (iii) intensity of infection - arithmetic mean of epg; (iv) negativation - proportion of positive persons who become negative four months after treatment; (v) reinfection - proportion of negativated persons who become positive again 12 months after treatment. Differences in intensity of infection among the successive surveys were evaluated at the 5\% significance level through one-way analysis of variance for repeated measures performed on the $\log _{10}(\mathrm{x}+1)$ transformed values of 
epg. Multiple pair-wise comparisons of epg between surveys were evaluated by Tuckey's HSD test (Sokal \& Rohlf 1995).

The data obtained from the follow-up group are depicted in the Figure and detailed below. Prevalence of infection decreased $9.6 \%$ (from $42.3 \%$ in March 1997 to 32.7\% in March 1999) after two treatments with oxamniquine and $11.5 \%$ (from $32.7 \%$ to $21.2 \%$ ) after one treatment with praziquantel. Prevalence of moderate to heavy infection decreased $3.8 \%$ (from $11.5 \%$ to $7.7 \%$ ) after two treatments with oxamniquine and $5.8 \%$ (from $7.7 \%$ to $1.9 \%$ ) after one treatment with praziquantel. Intensity of infection decreased $58.6 \%$ (from $55.8 \mathrm{epg}$ to $23.1 \mathrm{epg}$ ) after two treatments with oxamniquine and $68 \%$ (from $23.1 \mathrm{epg}$ to $7.4 \mathrm{epg}$ ) after one treatment with praziquantel. Mean epg from the March 1997, July 1997 and March 1998 surveys were significantly higher than the ones from July 1999 and March $2000\left(\mathrm{~F}_{(6,306)}=4.717 ; \mathrm{p}<0.05 ; \mathrm{HSD}=0.366\right)$. Negativation was $40.9 \%$ and $53.8 \%$ after the first and second oxamniquine treatment respectively, and $82.4 \%$ after the praziquantel treatment. Reinfection was $33.3 \%$ and $35.7 \%$ after the first and second oxamniquine treatment respectively, and $14.3 \%$ after the praziquantel treatment. Monthly relative abundance of $B$. straminea averaged 2.21 snails collected per person per minute between March 1997 and February 1999 and 1.99 snails/person/min between March 1999 and March 2000. Snail natural infection by $S$. mansoni averaged $0.03 \%$ between March 1997 and February 1999, and 3.9\%

A

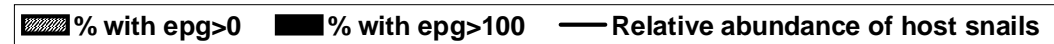
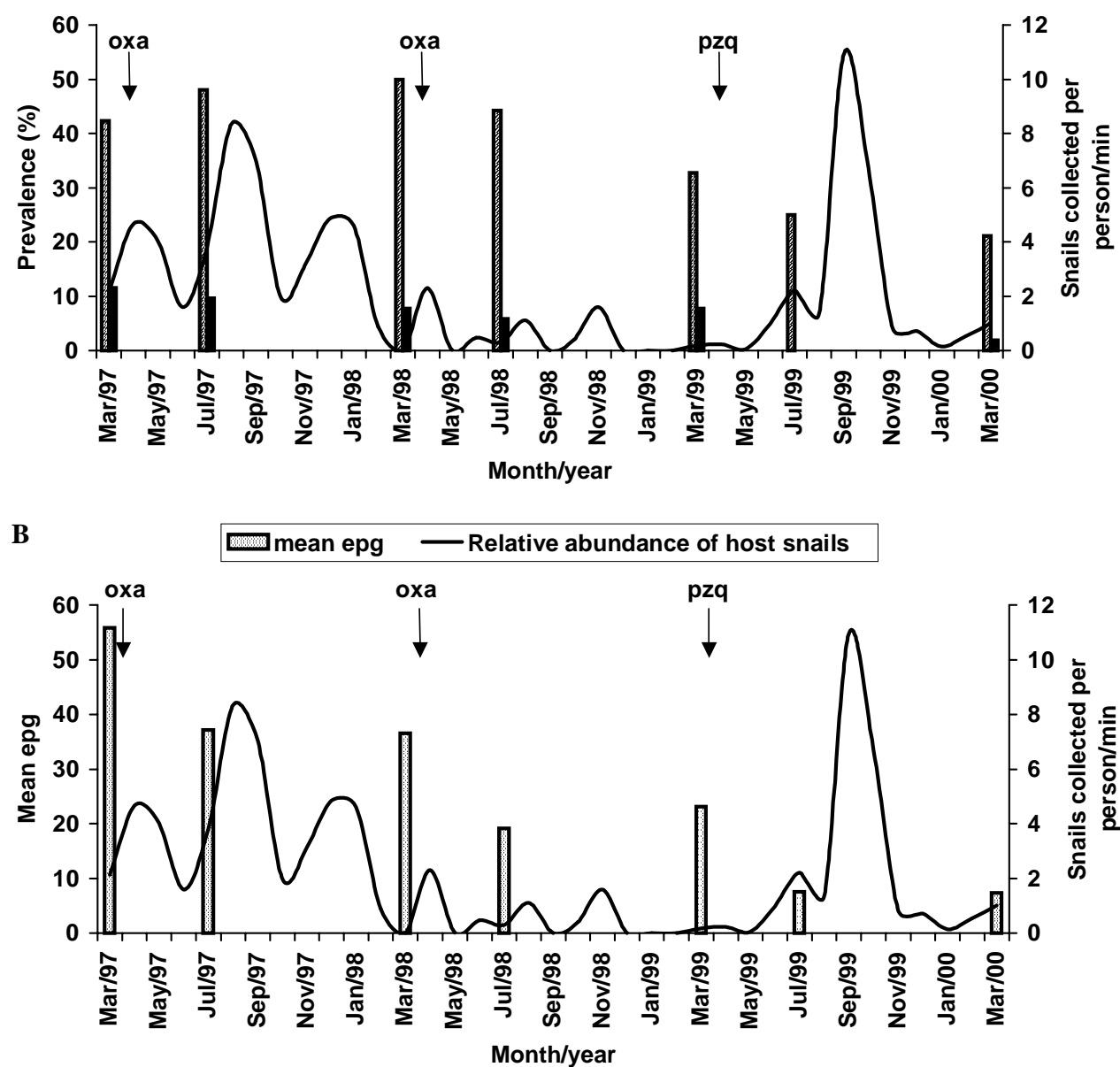

A: prevalence of infection (\% with epg $>0$ ), prevalence of moderate to heavy infections (\% with epg $>100)$; B: arithmetic mean of eggs per gram of feaces (mean epg) in a fully complying follow-up group of 52 persons (1-70 years old) from Araújo, a rural village in the sugar-cane zone of Pernambuco. Monthly estimates of the relative abundance of the local snail host, Biomphalaria straminea, are also given. The arrows indicate the times of medication with oxamniquine (oxa) and praziquantel (pzq). 
between March 1999 and March 2000. In March 2000 it reached $25.8 \%$ (20 positives out of 66 snails examined). The socioeconomic surveys showed that the population decreased $8.9 \%$, from 203 (March 1997) to 185 (September 1999) residents. During that period the village remained without sanitation or piped water and the average monthly income of $65.8 \%$ of the families was below the minimum wage.

The present study does not provide comparative information about the impact of oxamniquine and praziquantel in the study area because the patients were not randomly assigned to either treatment. However, it strongly suggests that replacing oxamniquine by praziquantel substantially reduced all infection indices in the follow-up group. In the short term, it is reasonable to assume an optimistic prognostic for the community as whole, since this group represented $28.1 \%$ of the population remaining in the village by the end of the study. This is relevant for schistosomiasis control at the community level in highly endemic areas, because only recently praziquantel has been introduced by the Funasa as the drug of choice in campaigns, and the present study is the first published report of its impact in the sugar-cane zone of northeast Brazil.

\section{ACKNOWLEDGEMENTS}

To Dr Ubiracy Guida, from the Funasa, Recife, PE, for assistance with chemotherapy; to Dr Eridan Coutinho and Dr Alexandre Bezerra Carvalho for providing facilities at the Centro de Pesquisas Aggeu Magalhães, and to the staff of the Estação de Biologia Experimental “Amilcar Barca Pellon”, São Lourenço da Mata, PE.

\section{REFERENCES}

Favre TC 1999. Impacto da Quimioterapia com Oxamniquine sobre a Infecção por Schistosoma mansoni em Duas Localidades da Zona Litoral-Mata de Pernambuco, $\mathrm{PhD}$ Thesis, Instituto Oswaldo Cruz, Rio de Janeiro, 148 pp.

Katz N, Chaves A, Pellegrino J 1972. A simple device for quantitative stool thick-smear technique in schitosomiasis mansoni. Rev Inst Med Trop São Paulo 14: 397-400.

Pieri OS, Barbosa CS, Moza PG 1998. Schistosomiasis control based on repeated chemotherapy in a rural village of the sugar-cane zone in northeast Brazil. Mem Inst Oswaldo Cruz 93 (Suppl. I): 259-264.

Sokal RR, Rohlf FJ 1995. Biometry:The Principles and Practice of Statistics in Biological Research, 3rd ed., WH Freeman and Company, New York, 887pp.

WHO 1993. The Control of Schistosomiasis, World Heath Organization, Technical Report Series, 830. 
168 Replacing Oxamniquine by Praziquantel • Lilian Beck et al. 